\title{
A TAM-Based Model of Technological Factors Affecting Use of E-Tourism
}

\author{
Ghazi Alkhatib, The Hashemite University (Retired), Jordan \\ Sinamis Tahsin Bayouq, University of Bedfordshire, Jordan
}

\begin{abstract}
In tourism, ICT provides new channels anywhere/anytime for tourism services that impacted how customers access and consume those services, hence the emergence of the concept of e-tourism. Internet can be used to attract customers, communicate with them, customize their required services, access international markets, and provide all types of touristic information through e-tourism platforms. The salient feature of this research is to identify the key technological factors that influence customers' acceptance and use of the services provided through e-tourism platforms. Other behavioral aspects related to the use of these services are treated as exogenous factors. The study constructed an e-tourism technology acceptance model (ETAM) concentrating only on technology-related factors. To assist in understanding how users will reflect in these four technological factors affecting the use of e-services, the model recognizes two moderating influential factors: trust and attitude. The model is augmented with exogenous factors as intervening factors related to customer's background.
\end{abstract}

\section{KEYWORDS}

Attitude, E-Tourism, Technological Factors, Technology Acceptance Model, Trust

\section{INTRODUCTION}

Tourism is one of the fastest-growing industries and among the most promising economic resources worldwide (Alrashid, 2012). Tourism constitutes a group of services, activities, and industries (accommodation, entertainment sites, sports centers, transportation, shops, and restaurants) that contributes to tourists' traveling experiences (Pitoska, 2013). Sustainable tourism is a proven tool for the development of any country (World Bank, 2019), with a substantial impact on the economic sector that significantly contributes to the global economy and development. The direct contribution is estimated by one statistic at USD 2.57 trillion in 2017 (Statista, 2019).

Tourism benefits countries by creating new job opportunities for employment in the hospitality, food, and crafts sectors, and promoting the country's local products boosting the local industry (Bennett, 2014). Moreover, tourism facilitates injecting cash flows in local communities, as tourists need food, clothing, medical services, transportation, gifts, and souvenirs. Other advantages of the tourism sector include preserving historical sites and encouraging locals to maintain their culture and traditions (Bennett, 2014). 
Legenderz is a multilocation company in the Middle East that operated in the marketing and advertising industry. It specializes in conducting scientifically driven business processes, namely devising strategies for start-ups, branding, creative advertising, and data science practices using scientific methods to extract knowledge and insights from structured and unstructured data (www. Legenerz.com). Detailed interview was conducted with the founder of the company's branch in Amman, Jordan to obtain some of these insights (M. Al Dabbas, personal communication, November $15,2019)$. In tourism industry, services are provided by four main parties; accommodations providers (hotels, motels...etc.), transportation providers (car rental agencies), experience providers (like paragliding or mountain climbing experiences providers) and travel agencies (who make the trip booking and might integrate services by the above mentioned to provide full tourism packages) (M. Al Dabbas, personal communication, November 15, 2019).

Tourism agencies use the Internet for communicating with customers, attracting prospects, customizing services, accessing international markets, providing tourism information and more (Zaidan, 2016). Many tourism agencies worldwide have digitized their tourism services using e-tourism platforms (websites/mobile) with unique multimedia and interactive features that create product trial-like experiences (Ku \& Chen, 2015). To offer high-quality e-tourism services, governments and travel organizations must prepare proper infrastructure (Hardware, software, and network). Furthermore, alliances with relevant intermediaries (flight agencies, local transportation agencies, hotels/accommodations, restaurants...etc.) that support full integrated e-tourism services must be considered (Ku \& Chen, 2015).

For tourism practitioners to remain competitive and sustain their businesses, they should adapt to the global flow and digitize their services, following a planned strategy to implement the best practices of e-tourism. Tourism agencies must understand their customers (needs, demand, culture ...etc.) to identify the factors that impact their behavioral intention and accommodate them on their websites (Shafiee et al., 2016).

This study keeps the basic structure of the original TAM but only concentrating on core technological factors that characterizes e-tourism services acceptance and satisfaction. Other behavioral factors are grouped together and treated as intervening variables.

In the ensuing discussions, the paper first provides review of literature and detailed systematic review research methodology. Then the paper has the main section on building the model of this research. Finally, the last section contains conclusions, recommendation, and future research.

\section{LITERATURE REVIEW}

E-tourism refers to the use of Internet and Communication Technologies (ICT) in tourism. This terminology describes the dependence of the tourism industry, tourism destinations, and tourists on applications of ICT to transform massive amounts of data to value propositions, through integrating and sharing real-time data, using sophisticated analytics, modeling and visualization to make functional decisions (Gretzel et al., 2015). Other authors state that e-tourism reflects using e-business in travel by digitizing of the value chain and transactions in tourism (hospitality, travel, catering and all tourism-related industries), where there is a set of internet standards and protocols that facilitate publishing information in new formats like text, images, videos, flyers, catalogs, Infographics, and even promotional teasers (Shafiee et al., 2016; Ukpabi \& Karjaluoto, 2017).

\section{Importance of E-Tourism}

Providing the e-tourism services online helps firms reduce administrative and communication costs, supports better integration with suppliers and vendors, provides better information management, better market understanding, and expanding geographical coverage (Pitoska, 2013; Dargah \& Golrokhsari, 2012). On the other hand, e-tourism has some disadvantages. Many customers prefer 
to make complicated transactions face-to-face for lack of trust in online transactions. E-tourism will cause traditional tourism agents' businesses to be displaced (Job loss), as travelers can explore destinations, accommodation, transportation, and activities, they can book and pay online (Dargah \& Golrokhsari, 2012). The demand for personalized services will grow based on customers' needs and interests, customers might be reluctant to put their private information online, such as credit card number, and passport number, in case it's misused (Dargah \& Golrokhsari, 2012). Moreover, creating and sustaining an integrated interactive e-tourism platform will increase outlays for tourism business owners. Those disadvantages might impede the adoption of technologies in the tourism industry.

E-tourism adoption starts from the tourism services providers' side (accommodations providers, transportation providers, experiences providers, and travel agencies) by automating all their operations and services along with having the financial resources required and the will to invest. Many customers use e-tourism platforms just to explore up-to-date information and ideas about recommended destinations, accommodations, transportations or things to do (activities) during a trip, some of them take the process further by booking related travel activities online, and others even pay online for the booked service/product. The goal of tourism agencies that adopted technology in their business is to assure customers full engagement with their e-tourism platforms to perform the whole tourism booking process online to guarantee their success and sustainability. Finally, achieving this goal may entail use of webcasts and electronic brochures, interactive multimedia, tour organization, and creating competitiveness among travel agencies (Guemide et al., 2019).

The growth of Internet users offers many opportunities and challenges to the tourism industry. The advancement of ICT increases the industry's competitiveness, which is characterized by speed, flexibility, transparency, and a variety of alternatives for destinations and prices (Pitoska, 2013).

\section{Model Constructs and E-Tourism}

The first attempt at understanding how users will positively interact with emerging technologies was the Technology Acceptance Model (TAM) by F. Davis in 1986 in his doctorate dissertation (Davis, 1986). The original model identifies four main constructs that leads to system usage, namely perceived usefulness, perceived ease of use, attitude toward use, and behavioral intentions to use. Researchers will augment the model by relevant external variable that are linked to perceived usefulness/perceived ease of use. Since then the model were subject to different variations and validation. Several studies augmented the model with relevant external variables to specific applications, such customer relationship model (CRM) (Abbad, et al. 2019; Richard, et al., 2007), and e-Tourism (Oumlil \& Ouhamane, 2016) using TAM constructs to predict e-tourism adoption by hotels in Morocco.

Other research diverged the model into different new models as reviewed by Lai (2017), and subsequently used by this study for comparing different factors or constructs in these models. For example, Chao (2019) developed a modified UTAUT to test students' satisfaction and trust in m-learning platform. In addition, the model incorporated gender, age, experience, and voluntariness of use as intervening variable. This latter aspect is used by this study by including different and additional factors. In another new model, the authors in (Sahli, et al., 2016) used "Tourism Web Acceptance Model" (T-WAM) for cross-cultural validation.

The objective of this paper is to develop a new model specifically for e-tourism concentrating on technological factors as the core of the building block of the model. The developed model kept the simple structure of the original TAM construct to allow for extensibility and convergence. Furthermore, the authors hope that this model will encourage researchers to use it in different contexts, such as regional, cultural, and application domains.

\section{RESEARCH METHODOLOGY}

Following the systematic review research methodology, the authors performed the steps below: 
- Examine current theoretical frameworks on technological adaptation models;

- Identify the main factors affecting e-tourism;

- $\quad$ Build the model for this research;

- Search for supporting secondary data to the determinant/factors in the framework;

- Provide recommendations for platform developers.

The following sections provide a detailed exposition of these steps.

\section{Current Conceptual Frameworks/Models}

The research will use a systematic review of several frameworks to be considered in this study to demonstrate and predict the behavioral intention to accept and use information technology in tourism. These frameworks are used to extract factors that affect the use of e-tourism services. Based on these discussions, the authors will construct the framework. The following list comprises the theoretical framework analyzed in this study.

- Technology Acceptance Model (TAM) and related extensions;

- Decomposed Theory of Planned Behavior (DTPB);

- $\quad$ The Unified Theory of Acceptance and Use of Technology (UTAUT);

- Tourism Web Acceptance Model (T-WAM).

Table 1 provides a summary of an extensive analysis of these models, which maps these frameworks/models to their correspondent factors, and their related citations.

Comparing the theories amongst each other, they all agree on the importance of perceived usefulness/benefit and perceived ease-of-use. However, TAM has limitations in terms of explanatory power and doesn't include social/subjective norms as a factor impacting behavior intention, whereas this is considered an important determinant theorized by TAM2, DTPB, UTAUT and T-WAM (Ajibade, 2018; Sahli \& Legohérel, 2015). Authors claimed that TAM cannot be used to address customers' intention to use technology in real business context, because the perceived-usefulness and perceived ease-of-use are not the only important factors for technology acceptance as the availability of online/YouTube tutorials help in this matter. Also, as the authors stated, the perceived enjoyment must be focused on to assure customers' acceptance/satisfaction (Ajibade, 2018). Moreover, TAM does not directly relate the perceived usefulness and perceived ease of use to customers' trust and attitude towards using technology, which are the moderator variables in the conceptual model of this study. UTAUT is a powerful model with a constricted structure and high explanatory power but failed to examine other factors (like perceived enjoyment, control, and compatibility) that highly impact the intention to use e-tourism platforms and might uncover new relationships other than the existing ones (Lai, 2017). The DTPB surpasses TAM and UTAUT by including perceived behavioral control and compatibility factors, which are crucial in technology acceptance, but at the same time overlooks an important factor of the perceived enjoyment (Lai, 2017). T-WAM is specialized in e-tourism and includes factors that cover the entire spectrum of determinants used in other theories.

\section{Technological Factors Affecting E-Tourism}

The four technological factors to be discussed against mentioned behavioral factors of T-WAM and DTPB frameworks to assess their impact on customers intention to use e-tourism platforms are security of the platform, supporting mobile payments, platform design and quality, and having mobile applications. As the following sections show, those factors cannot be explained separately as they overlap in many areas, as well as their relationships to the mediator factors. 
International Journal of Tourism and Hospitality Management in the Digital Age

Volume 5 • Issue 2 • July-December 2021

Table 1. Summary of research on factors, frameworks, and related citations

\begin{tabular}{|c|c|c|c|c|c|c|}
\hline \multirow{2}{*}{ Factors } & \multicolumn{5}{|c|}{ Frameworks } & \multirow{2}{*}{$\begin{array}{c}\text { Cited } \\
\text { Research }\end{array}$} \\
\hline & TAM & TAM2 & DTPB & UTAUT & T-WAM & \\
\hline Perceived-Usefulness & $\checkmark$ & & $\checkmark$ & & $\checkmark$ & \multirow{2}{*}{$\begin{array}{l}\text { (Davis,1989), } \\
\text { (Sahli \& } \\
\text { Legohérel, } \\
\text { 2015), } \\
\text { (Suh \& Han, } \\
\text { 2002) }\end{array}$} \\
\hline Perceived-Ease-of-Use & $\checkmark$ & & $\checkmark$ & & $\checkmark$ & \\
\hline Subjective norm & & $\checkmark$ & $\checkmark$ & & $\checkmark$ & \multirow{2}{*}{$\begin{array}{l}\text { (Venkatesh \& } \\
\text { Davis, 2000), } \\
\text { (Al-Majali \& } \\
\text { Mat, 2019), } \\
\text { (Suh \& Han, } \\
\text { 2002), (Sahli } \\
\text { \& Legohérel, } \\
\text { 2015) }\end{array}$} \\
\hline Voluntariness-image & & $\checkmark$ & & & & \\
\hline $\begin{array}{l}\text { Individual level (IT) } \\
\text { Knowledge }\end{array}$ & & & & & & $\begin{array}{l}\text { (Venkatesh \& } \\
\text { Bala, 2008) }\end{array}$ \\
\hline Attitude & & & $\checkmark$ & & & $\begin{array}{l}\text { (Robbins \& } \\
\text { Judge, 2017) }\end{array}$ \\
\hline Trust & & & & & $\checkmark$ & $\begin{array}{l}\text { (Maduku, } \\
\text { 2016), (Suh \& } \\
\text { Han, 2002) }\end{array}$ \\
\hline Satisfaction & & & & & $\checkmark$ & $\begin{array}{l}\text { (Maduku, } \\
\text { 2016) }\end{array}$ \\
\hline $\begin{array}{l}\text { Perceived Behavioral } \\
\text { Control }\end{array}$ & & & $\checkmark$ & & $\checkmark$ & $\begin{array}{l}\text { (Sahli \& } \\
\text { Legohérel, } \\
\text { 2015), (Al- } \\
\text { Majali \& Mat, } \\
\text { 2019), (Suh \& } \\
\text { Han, 2002) }\end{array}$ \\
\hline Compatibility & & & $\checkmark$ & & $\checkmark$ & $\begin{array}{l}\text { (Sahli \& } \\
\text { Legohérel, } \\
\text { 2015), } \\
\text { (Davis, 1989), } \\
\text { (Al-Majali \& } \\
\text { Mat, 2019), } \\
\text { (Bagozzi, } \\
\text { 2007), } \\
\text { (Suh \& Han, } \\
\text { 2002) }\end{array}$ \\
\hline Perceived enjoyment & & & & & $\checkmark$ & $\begin{array}{l}\text { (Suh \& Han, } \\
\text { 2002), } \\
\text { (Sahli \& } \\
\text { Legohérel, } \\
\text { 2015), } \\
\text { (Perea y } \\
\text { Monsuwé et } \\
\text { al., 2004) }\end{array}$ \\
\hline Perceived risk & & & & & $\checkmark$ & $\begin{array}{l}\text { (Suh \& Han, } \\
\text { 2002), } \\
\text { (Sahli \& } \\
\text { Legohérel, } \\
\text { 2015) }\end{array}$ \\
\hline Perceived benefit & & & & & $\checkmark$ & $\begin{array}{l}\text { (Suh \& Han, } \\
\text { 2002), } \\
\text { (Sahli \& } \\
\text { Legohérel, } \\
\text { 2015) }\end{array}$ \\
\hline $\begin{array}{l}\text { Performance expectancy } \\
\text { (Perceived usefulness) }\end{array}$ & & & & $\checkmark$ & & $\begin{array}{l}\text { (Venkatesh et } \\
\text { al., 2003), } \\
\text { (Lai, 2017) }\end{array}$ \\
\hline
\end{tabular}




\section{Security Factor}

Security mechanisms control access to the system's data and operating system files. For this study, security systems have the following dimensions (Confidentiality-Integrity-Authentication-SafetyPrivacy-Cybersecurity). Secure systems must protect sensitive information from being accessed by unauthorized party/parties (Confidentiality). With global access to data in e-tourism, the system must employ a complex user identification procedure (Authentication). Users perform tasks without being impaired by any disruption in the external/internal environment (Integrity) and without portraying any risk of damaging people or property (Safety). In the global environment of e-tourism, users' personal and sensitive data must be protected from unauthorized use and distribution (Privacy), and also against cyber-attacks (Cybersecurity). In Mobile commerce (M-Commerce), transactions are performed over an open system environment, and consequently generate significant and critical security concerns (Tussyadiah et al., 2019; Kumar \& Goyal, 2016). Since the parties involved in e-tourism (tourism agencies-customers-third parties) communicate over cyberspace on the Internet which operates globally through multiple stations and nodes, e-tourism platform developer must take serious attention to security issues to ensure all stakeholders are authenticated to operate through these platforms safely and to be immune from any negative drawback from lack of effective security measures (Al-Mamary et al., 2014).

The security level/control that the users are exposed to when they conduct transactions over e-commerce platforms is the main trigger for their perceived trust, which positively affects their intention to use online platforms (Kim et al., 2011). E-tourism platforms must attain a high-security level since they aim to secure financial transactions for customers' bookings/reservations.

E-tourism agencies must protect their platforms against malicious attacks, offer security policy for users, secure shopping guarantees, and privacy policy mechanisms. These measurements should participate heavily in enforcing customers' trust and positive attitude towards using e-tourism platforms (Kisswani \& Bakri, 2010; Yoon \& Occeña, 2015). Khan (2019), explains a detailed exposition of the critical detriments of the security measures in e-commerce, and provides directions that will lead to customer confidence in e-commerce activities.

Whenever e-tourism platforms can secure the transactions of their clients, customers will emphatically increase their trust and feel comfortable to release their private information and do their online payments confidently. This will push the e-tourism industry forward to participate as one of the main economy drivers globally (Prasidya, 2018). However, based on (Dewanjee \& Vyas, 2016) clear policies should be in place to define computer crimes and develop legislations fostering confidence in users that whatever happens they will be protected by such legislations.

The perceived usefulness/benefits and customer's trust in e-tourism platforms that have more solid security measurements are ranked higher than other sites that are not well secured. Consequently, these latter sites are used by users just to explore destinations and prices without doing actual transactions. The higher the perceived usefulness/benefits and the trust, the more positive attitude customers will have, this will directly impact their intention to use the platform. At the same time, providing and sustaining high-security measurements in e-tourism platforms increases the operational expenses on service providers, which might present reluctance from business owners to invest in this field and may delay adopting e-tourism platforms (M. Al Dabbas, personal communication, November 15, 2019).

\section{Having Mobile Applications}

Since most people use their mobile phones for online processes because they are inherently flexible, authors hypothesized that having compatible mobile applications for e-tourism platforms will probably increase the user base, providing flexible, useful/adequate and easier to use environment (Tan et al., 2017). Furthermore, a continuous increase in device capabilities enables users to perform more tasks (Tan et al., 2017; Hoehle \& Venkatesh, 2015). The existence of mobile applications has created a new business model with new channels of mobile marketing (Wang et al., 2013). With mobile 
downloadable applications receiving valuable attention from users around the world, business owners (like tourism agencies) need to understand customers' perception of mobile applications used as a means of differentiation to gain maximum benefit and sustain their business competitiveness (Wang et al., 2013). Mobile applications provide a high level of personalization and convenience, allowing customers to search for products/services, detailed features, compare prices, and get discounts/ promotions. They can make use of push notifications and work offline when needed contents are downloaded (Tan et al., 2017). Researchers argued that mobile applications offering simple layout and tutorials for first-time users are easier to use than desktop apps and websites. This will provide the mobile application users with an enjoyable experience, and keep them in the mobile applications environment for longer periods, leading to customer loyalty, increasing the interaction with mobile shoppers, boosting promotions effectiveness, and having positive impact on customers' attitude towards using e-tourism platforms (Tan et al., 2017).

Other researchers stated that supporting mobile applications enhances customers' touristic experience, as they can use mobile applications even during their trips to search for and locate desired restaurants, transportation, medical services, activities, ...etc. (Tan, et al., 2017; Ukpabi \& Karjaluoto, 2017). A report prepared by (GoodWorkLabs, 2019) states that mobile applications are the $7^{\text {th }}$ most downloaded apps, where $60 \%$ of global users download travel/tourism applications into their smartphones. Utilizing mobile applications in tourism massively changed the way services are offered, accessed and used. This technology enhanced all tourism transactions (exploring, booking, paying). In an article, the authors stated that mobile applications positively influence the acceptance/ adoption of e-tourism platforms (Ukpabi \& Karjaluoto, 2017).

A study proposed that mobile applications developed for travel businesses must be customizable based on tourists' needs. Managers should combine e-tourism websites features and maintain a positive perception of destination images to assure customers acceptance/adoption (Chang, et al., 2016). Despite all the benefits, we believe that some users may think that mobile applications presented over small screens like mobile phones and tablets limit their effective browsing and searching freedom over the web. This could damage the perception of the e-tourism platform brand. E-tourism platform developers must address this issue carefully, testing the mobile application under different smartphone types and operating system environments.

Many challenges that face mobile application developers: the limited input facilities, limited screen size and other specifications like memory size and processing capacity. Developers must find innovative ways to make mobile applications efficient, easy to use and navigate with a simple friendly design. In other words, they must seek ways on how to integrate mobile applications in customers' daily lives to provide useful, easy to use functions (Ukpabi \& Karjaluoto, 2017; Hew et al., 2015). Furthermore, developers should understand the underlying motives/values that drive customers to adopt/use e-tourism platforms/applications (Wang et al., 2013).

Moreover, if tourism agencies support mobile applications when transforming to e-tourism, their brand will remain on customers' home-screen even when they close the mobile applications, permitting higher probability to be opened and used again. Their brand will also be available on the app stores (iOS/Android) providing a new channel for raising brand awareness and attracting new customers. Researcher further concluded that supporting mobile applications is positively related to customers perceived usefulness, perceived benefit, enjoyment and perceived ease of use, where customers find them compatible with their lifestyle, needs and shopping preferences, leading to higher probability of accepting/using e-tourism platforms (Ukpabi \& Karjaluoto, 2017; Hew, et al., 2015). Also, due to the direct nature of the screens' "Touch" feature, users will sense more control over the device like smartphones and tablets (Brasel \& Gips, 2014), making the experience easier and more useful in their perspectives. This, in turn, will increase the probability of accepting/using e-tourism mobile platforms (Sahli \& Legohérel, 2015). 


\section{Supporting Online/Mobile Payments}

E-tourism platforms supporting online payment processes invoke smooth, compatible, and convenient users' engagement (Slade et al., 2015). Mobile Internet has been evolving rapidly worldwide and the number of global Internet users is growing very fast, which indicates the importance of e-commerce platforms in all industries. In the beginning, mobile payments were not widely adopted by users because of the perceived risk and high uncertainty attached to the system. However, mobile payments attracted the attention of enterprises as the key application supporting e-businesses (Zhou, 2014; Slade et al., 2015). Therefore, building users' trust in mobile payments is a pre-requisite to expedite their adoption.

Mobile payments facilitate users' ability to access financial services and information, like balance checking, money transformation, and payment management using mobile devices. Mobile payments integrate mobile devices with an authenticated payment system to give users the ability to conduct online financial transactions over a mobile network using mobile devices. This was facilitated through the revolution of network technologies and mobile devices, where users fill their credit/debit card information when setting up the application, information is then stored and doesn't have to be entered every-time the user accesses/uses the application (Slade et al., 2015).

Mobile payments are used for wide ranges of applications, like paying utility bills and buying goods or services. In e-tourism, mobile payments are essential to complete the whole transaction of the tourism booking process as they increase perceived usefulness/benefit and ease of use. Authors argued that when customers are provided with secure, rich e-tourism platform and proper training on the use of the system, they will have a higher level of satisfaction, generating trust and positive attitude towards using the e-tourism platforms (Ukpabi \& Karjaluoto, 2017; Qatawneh et al., 2015).

The main advantage of mobile payments in e-tourism is ubiquity, where users are freed from spatial constraints and can conduct mobile payments from anywhere at any time, providing great convenience for customers. Mobile payments increase reachability, compatibility, and convenience in users' perception, and affect users' intention to use mobile payments (Zhou, 2014).

In their article, (Qatawneh et al., 2015) demonstrated that mobile payment systems were found to increase transaction speed, reduce transports costs, robbery, and enhance merchants' liquidity, and improve buyers' online shopping satisfaction. Despite the mentioned advantages of mobile payments, some tourists may still prefer cash payments, where lack of trust is the main reason behind the resistance to adopt mobile payments due to the vulnerability of networks to hackers and information interception, which will negatively affect customers' trust and attitude towards using mobile payments (Slade et al., 2015).

Mobile payments systems are highly affected by the "Security" factor, which plays an essential part in customers' acceptance of making financial transfers. Authors in (Slade et al., 2015) emphasized that customers' trust is the most significant predictor of their behavior towards mobile payment systems and the process of adopting them, conversely negatively affecting the perceived risk of using a mobile payment system. Studies demonstrated that mobile payment adoption was more successful in Asian and developing countries than Europe and North America (Slade et al., 2015).

In this context, tourism agencies should build users' trust in their e-businesses platforms (websites/ mobile applications) and the associated online/mobile payments systems to retain customers, guarantee business success and continuous usage by customers/prospects. They must ensure they are offering a solid, reliable, and secure mobile payment system; they should also create awareness for the target audience about this system showing the latest security measures implemented on e-commerce platforms. This should increase customers' perceived usefulness/benefit (performance expectancy), ease of use, enjoyment, and satisfaction, positively affecting their trust and attitude towards using/ adopting the e-tourism website/mobile applications with mobile payment system, according to (Chen \& Li, 2016; Zhou, 2013; Sahli \& Legohérel, 2015). 


\section{Design and Quality of the User Interface}

Having a website is essential for digitizing business to improves productivity, communicates the functionalities of the organizations' e-services and stimulates market growth (Ku \& Chen, 2015). Because the number of mobile phone users is highly increasing every year, and since people perceive using e-services through mobile applications easier, more flexible and convenient, having a well-designed mobile application is mandatory for businesses to sustain their competitiveness (Wang et a., 2013). Through e-tourism websites/mobile applications, tourists can read reviews/ feedback of other tourists, explore, book the whole trip online, pay and then share their reviews/ feedback. A platform (website/mobile application) with user-friendly designs makes using e-tourism platforms easier and more enjoyable, hence increasing customers' perceived usefulness/ benefit and satisfaction (Chen et al., 2010).

Many features contribute to the website/mobile application design quality and customers' satisfaction, trust, attitude, and acceptance. Security indicators assure platforms' high quality, the protection of personal data and transactions increasing customers' trust and website/mobile application usability. Being error-free, customer-oriented, providing prompt services to tourists, having an attractive logo, guaranteeing orders completion, using suitable homogeneous shapes, colors, high-resolution images and backgrounds, simple navigation, creatively packaging and customizing information content, are all factors that must be considered when building e-business platforms (Ku $\&$ Chen, 2015). Furthermore, having a search engine on the website/mobile applications is crucial, as a starting point for most website/Mobile applications users especially in e-tourism. A search engine is computer software that searches for terms/keywords in a document, website/mobile applications, newsgroups, or informational banks, gathers and analyzes information, then stores results in databases (Shafiee et al., 2016). If search activities are optimized using search engine optimization (SEO) techniques, they will achieve higher ranking for a website in search engine lists, which in turn increases the probability that users will visit/use the website (Khraim, 2015).

In e-tourism, website/mobile application design is one of the most important factors impacting customers' intention to using related e-services and contributing to business sustainability. Studies argue that a website's/mobile applications' attractiveness and ease of use highly affect retention time and users' intention to accept/use the website/mobile applications. Results showed that high-quality website design positively contributes to customers' satisfaction, perceived enjoyment (how much they enjoy the website/mobile applications), perceived usefulness/benefit (customers' recognition of information quality), and trust (Shafiee et al., 2016; Ku \& Chen, 2015). However, people have different tastes and standards regarding what is attractive and beautiful, therefore, adding unique flavors of the website/mobile applications can't be easily standardized. Furthermore, customer satisfaction determines the individual's affective reaction towards the acceptance/usage of computer applications (Hill et al., 2019). Previously mentioned points can motivate customers to recommend the website/ mobile applications to their peers, increasing the number of prospects (Ku \& Chen, 2015).

Website/mobile application design refers to the technological side of the website (i.e. appearance, layout, and navigation) (Ku \& Chen, 2015). Website/mobile application design is decomposed into 3 categories: visual design, social cue design, and content design. Visual design is the eye-catchy, attention-grabbing, creative visual quality of a website/mobile application. Once accessed, the graphical and structural elements create a first impression on customers. Aesthetic visual design emotionally attracts customers to the website/mobile applications. This includes the usage of colors, graphics, layout/space, and information presentation (Shafiee et al., 2016).

The author in (Hasan, 2016) concluded that website/mobile applications with hideous visual design may upset users and make them feel irritated. UXarabia - a specialized user experience company - stated that simple navigation is another essential aspect for customers to accept/use e-business platforms (in this study, e-tourism platforms) leading to more users (travelers) accessing the platform, and streamlining their tasks and enhancing their enjoyment/playfulness. User experience statistics proved that users spend a longer time surfing through simple websites/mobile applications, 
hence facilitating customers' acceptance to use those e-platforms (UXarabia, 2019). Simple navigation can be achieved by having proper titles, hypertexts, and links back to website/mobile applications homepage from all sub-pages. Hypertexts enable accessing a large amount of content quickly (Devi \& Verma, 2018; Ku \& Chen, 2015).

The social cue design is related to increasing customers' engagement in the website/mobile applications through adopting social-media applications like photos, video streams and social blogs/ forums within the website/mobile applications, where content design relates to the website's/mobile applications' informational components (graphics/text). Those include company information (contactinformation, background, and FAQ), and detailed product/service information (description, features, price, delivery/return policy).

The author in (Hasan, 2016) suggested that e-business owners (like e-tourism agencies) must pay great attention to the content design of their website/mobile applications to assure that users aren't overwhelmed by irrelevant information that might distract them, and prevent them from using the platform in future. Content design is proved to increase "User Information Satisfaction", which refers to how much users find the provided information on the website/mobile applications effective, useful, and meet their requirements.

Another catalytic function of the interactivity of website/mobile applications, which is the reciprocal action between humans and technological systems, demonstrating the extent to which users can modify the content of a systems' environment by implementing social interactions, information sharing, feedback, tourism news, and location-based maps, fostering customers' perceived-control, enjoyment, satisfaction, and attitude towards the e-tourism website/mobile applications. High interactivity implies the effectiveness and availability of user support tools on the website/mobile applications, positively contributing to the website/mobile applications design quality and e-tourism service quality, giving customers a sort of control over the exchanged travel information, explore, book, and pay for tourism services (Ku \& Chen, 2015).

The service quality of the website/mobile applications must cover the whole service delivered by the travel agency through their e-tourism platform, as researchers proved that the service quality is highly related to customers' satisfaction with their online tourism experience (Ku \& Chen, 2015). Focusing on the three design categories (visual design, social cue design, and content design) along with "Interactivity" and "Service Quality" is essential in e-tourism industry, as researchers assured that those factors are positively pertinent to users attitude, trust, perceived-enjoyment, perceived easeof-use, and perceived-benefit/usefulness increasing the probability of accepting/using the website/ mobile applications (Sahli \& Legohérel, 2015; Shafiee et al., 2016; Ku \& Chen, 2015).

Another design issue is to introduce some form of front-end user interface intelligence powered by back-end technologies, such as big data, Artificial Intelligence (AI), and Machine Learning (ML). Using big data in tourism creates great opportunities and poses significant challenges to improve the competitiveness of tourism destination and optimizing performance (Ardito, et al., 2019). AI and ML allow the use of sophisticated intelligent technologies in the tourism industry (Zlatanov \& Popesku, 2019). Application areas of these technologies in e-tourism are based on current technologies: recommendation system using traditional data analytics of data and text mining (Borràs et al., 2014), Big Data (Yang \& Stienmetz, 2018), or AI and ML (O.T.T., 2019). These include the personalization of users (individuals or segments), preferences for hotel reservation and room services, estimation of hotel rates in the dynamic pricing process in the tourism industry, tailored offers for most valuable customers, customer service and chatbots, smart travel assistance dealing with travel contingencies due to cancellations and weather conditions, fraud detection, augmented reality, mobile tour guide.

\section{BUILDING THE MODEL OF THE PAPER}

Based on the previous review of current technological factors, establishing the model required finding patterns/categories, and looking for links/relations between the key core "Technological Factors", 
"Customer attitude/trust" and the intention to use "E-Tourism Platforms", to critically synthesize results. While the authors used previous studies for the selection of the different factors affecting the adaptation of new technologies, the authors followed the following distinctive features for building the model:

- Rather than populated the model with many factors and relationships, the authors kept the original TAM-like structure of identifying limited specific factors;

- The model has a one-directional sequence of cause-and-effect relationships, also reflecting the original TAM model approach;

- The model concentrated only on technological factors. Other behavioral factors, such as perceived usefulness, perceived-ease-of-use, behavioral intentions, and subjective norm are included indirectly in the technological factors, moderating factors, and/or intervening variables;

- To explore customers' reactions to the model perception, some background factors are included as external behavioral intervening factors;

- The model building method will facilitate future testing using the Structured Equation Model (SEM), as well as testing the model itself alongside the effect of the intervening variables.

The framework identifies three categories of factors: independent variables, mediating parameters, and dependent variables. The first two were further assigned multiple factors, as shown in Figure 1.

Figure 1. ETAM: The conceptual framework

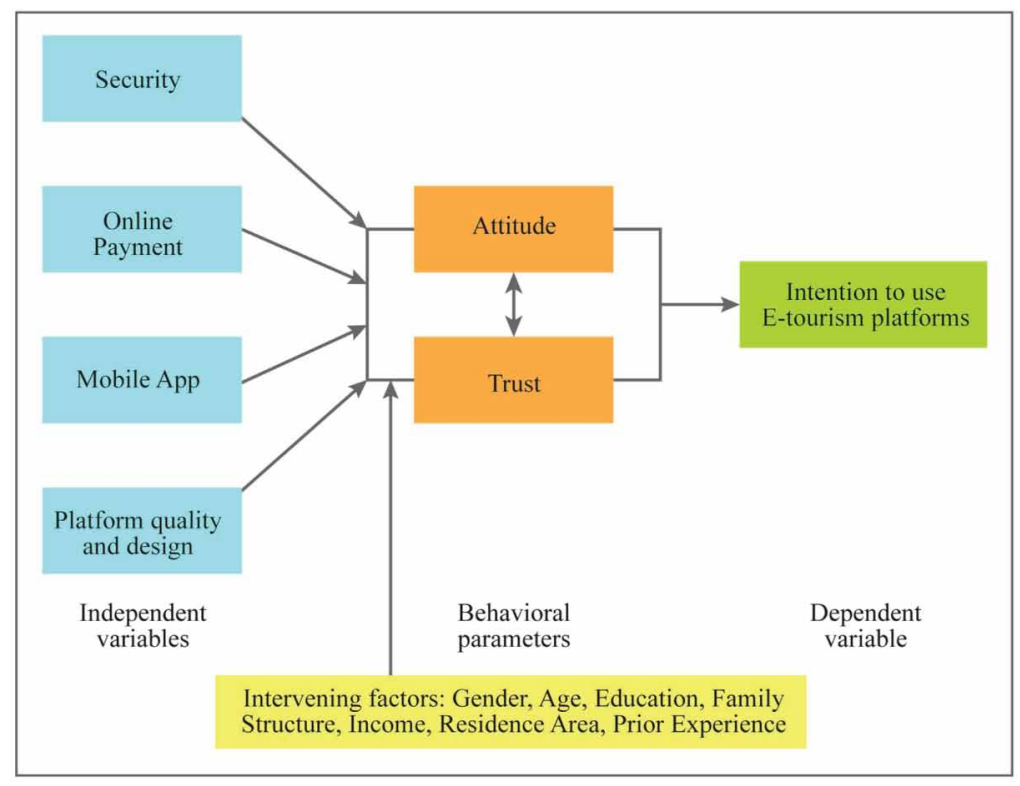

The E-tourism Technology Acceptance Model (ETAM) introduces specific technology factors as independent variables, then links those to use of e-tourism platform, through two mediating factors, namely "Attitude" and "Trust". Finally, rather than introducing factors such as social norms, level of IT knowledge, and Subjective norm, the model used customers' background as intervening variables. These latter factors are treated outside the main model, facilitating understanding the behavior of the 
model as used by consumers. The ensuing discussions present an analysis of these four independent factors and the two mediated factors.

\section{Security}

After reviewing the security-related resources, the analysis concluded that security is a major concern for e-commerce users especially for the third phase of e-tourism platform usage (exploring - booking - paying). The linkage between financial transactions and dealing over intangible channels was considered as high perceived risk by users especially that they cannot control the whole process starting from their intention to pay until they receive a confirmation of their order. However, customers prefer to control the whole process, where they can get this service directly from travel agencies.

\section{Having Mobile Applications}

The second objective of this study is to explore how having mobile applications affects customers' attitudes towards e-tourism services and the intention to use them. As mentioned earlier, using smart devices (mobiles/tablets) has become part of any society for communication/socialization and browsing purposes.

As a result of the user-experience analysis, we believe that tourism platforms require high-quality images and videos to build up rich content in these mobile applications. This should attract users and generate more interest in the promoted locations/services. Presenting marketing content in the highest quality guarantees strong engagement and influence customers' satisfaction, especially for people who value portability and reachability.

\section{Supporting Mobile Payments}

The third factor in this study relates to understanding how supporting mobile payments in e-tourism platforms can impact customers' trust/attitude towards e-tourism services and the intention to use them.

In e-tourism, mobile payments are important to complete the whole booking process. Mobile payments represent the third stage in using e-tourism platforms (exploring-booking-paying). According to the references mentioned in the literature review, many tourists tend to use websites/ mobile applications for the first two phases (exploring and booking) where they leave the last phase (paying) to be completed face-to-face through traditional payment methods at agencies' offices.

\section{Website/Mobile Applications Design and Quality}

The fourth variable in the model help in understanding how "Design and Quality" of e-tourism platforms can affect customers' attitude towards e-tourism services and the intention to use them.

Website/mobile applications interface is the first thing that customers face when attempting to use e-tourism platforms. If that interface was eye-catchy with high interactivity, simple construct and navigation, the probability of using and spending more time on that platform will be high. Moreover, the content design (informational component) of the e-tourism website/mobile applications is essential, as providing only relevant high-quality information and graphics will retain customers and motivate them to keep using the platform whenever they intend to plan for trips, consequently, leading to user information satisfaction as mentioned in the literature review.

Since the website/mobile applications interface is the first stage where customers get their first experience with the e-tourism platform, such exposure can be considered as a very influential factor. With a positive first impression, customers decided to keep on exploring within the website/mobile applications, then they will start considering the other technological factors (security, having mobile applications, and supporting mobile payments). Simple, interactive, eye-catchy e-tourism website/mobile applications with rich relevant content increase customers' perceived enjoyment, perceived usefulness/benefit, ease-of-use and therefore positively impact their attitude towards using that platform. 
Accordingly, website design and quality are considered influential technological factors on customers' attitudes and intention to use e-tourism platforms.

\section{Mediator Factors}

In the preceding discussions, the effect of the selected technological factors on attitudes and trust were embedded where appropriate. In this section, definitions of the two mediating factors are provided. These two factors encompass several of the behavioral factors mentioned in TAM-related models. Furthermore, the review of the literature highlights several aspects of the importance of these two factors. Attitude and trust were used as moderator factors influencing the relationship between the addressed technological factors and customers' intention to use e-tourism platforms. In the model's chart and as supported by the discussions, a line is drawn between the two reflecting their mutual effects.

\section{Attitude}

One psychologist researcher distinguishes between attitude and perception (Pickens, 2005). The author identifies three dimensions of attitudes: Actions, feeling, and belief. It has mutual effect between the individual and the social world each affecting the other. Attitudes as such, affect our decisions, direct our behavior, and impact what we remember selectively from our experiences. On the other side, the author states that perception is subject to interpretations of individual to stimuli based on prior experiences. However, these interpretations may be substantially different from reality.

In organizational context, attitudes are evaluative statements, which reflect how individuals feel about objects, people, or events. (Robbins \& Judge, 2018). They describe the negative or positive behavior of individuals towards intention to accept, use and adopt new technologies. The authors felt that Attitudes is more appropriate to be included as the moderated factor than perception. This stance is supported by discussions of factors in the models considered in this paper. From table 1, the models suggest that all the following behavioral parameters impact customers' intention to use e-tourism platforms; perceived usefulness, perceived ease of use, compatibility, perceived enjoyment, subjective norms, perceived behavioral control, perceived risk and perceived benefit. DTPB relates attitude to three variables: perceived usefulness, perceived ease of use, and Compatibility. Where Compatibility is defined as the extent to which an innovation is perceived to be consistent with past experiences, present values, and needs of prospects. Researchers hypothesized that when technology is consistent with past experiences, present values, and needs (what they already know/use), customers are inclined to accept/adopt new technologies. (Sahli \& Legohérel, 2015; Davis, 1989; Al-Majali \& Mat, 2019). Besides, perceived enjoyment - which refers to the potential entertainment of Internet shopping - (Perea y Monsuwé et al., 2004) can also affect attitudes towards using new technologies.

\section{Trust}

Trust is defined as the individual's belief that the commitment of another party can be dependable, and that in unexpected circumstances that party will act decently towards him/her (Maduku, 2016; Suh \& Han, 2002). Also, perceived benefit is the individual's belief that using the online transaction of a company's website will be of great advantage and will support his/her deal. (Sahli \& Legohérel, 2015). To accept using new technology, users must be assured of risk-free access and of providing them with the intended benefits. In another study, those mentioned behavioral parameters have a direct impact on customers' attitudes towards using e-tourism platforms. (Suh \& Han, 2002; Sahli \& Legohérel, 2015). A study on m-mobile learning use by students concluded that trust significantly affects system use (Chao, 2019).

Therefore, for individuals to accept using new technology, it must be a risk-free process and provide them with the intended benefit. In this study's conceptual model, customers' trust is used as the second moderator factor. 


\section{Intervening Variables}

These variables belong to users' background, which include Gender, Age, Education, Knowledge of IT, Family Structure, Income, Residence Area, and Prior Experience.

\section{CONCLUSION, RECOMMENDATIONS, AND FUTURE RESEARCH}

\section{Conclusion}

In this paper, the authors established an E-tourism Technology Acceptance Model (ETAM) to guide the development of effective and efficient e-tourism platforms. Based on an extensive systematic review of literature, these e-services must follow the requirements as delineated in the four factors of the independent variables: security, mobile applications, mobile payments systems, and user interface quality/design of e-tourism services. Satisfying these requirements will enhance users' attitudes towards using these platforms and will create a feeling of trust in using them as well. Consequently, these two factors, trust, and attitudes, are includes as moderating factors that affect the use of these services. Detailed information on respondents' background is included as intervening variables and treated as an exogenous factor of the ETAM technological factors affecting customers' behavior of using the model.

\section{Recommendation}

The model of the study should assist tourism agencies and e-tourism platform developers to implement the best practices that achieve customers' acceptance, engagement, and satisfaction with e-services. To facilitate and encourage users' satisfaction and acceptance of these e-services, countries need to develop software and internet/network policies and guidelines, as well as a strong coverage of Internet access.

\section{Future Research}

The authors' future researches aims at testing the framework developed by this study with survey sampling using advanced statistical analysis and Structured Equations Modeling (SEM) techniques. 


\section{REFERENCES}

Abbad, M., Alkhatib, G., Al-Qeisi, K., \& Jaber, F. (2019). Jordan banks' perceptions of customer relationship management: a TAM-based investigation. J for Global Business Advancement, 12(6), 820. doi: 10.1504/ JGBA.2019.107739

Ajibade, P. (2018). Technology acceptance model limitations and criticisms: Exploring the practical applications and use in technology-related studies, mixed-method, and qualitative researches. Library Philosophy and Practice, 1-13.

Al-Majali, M., \& Mat, N. (2019). Application of decomposed theory of planned behavior on internet banking adoption in Jordan. Icommercecentral.com. Available at: http://www.icommercecentral.com/openaccess/application-of-decomposed-theory-of-planned-behaviour-on-internet-banking-adoption-in-jordan. php?aid=38379

Al-Mamary, Y., Shamsuddin, A., \& Aziati, N. (2014). The meaning of management information systems and its role in telecommunication companies in Yemen. American Journal of Software Engineering, 2(2), 22-25.

Alrashid, S. (2012). Internet adoption in the Gulf Cooperation Council's tourism industry. New Media and Mass Communication, 3, 36-42.

Ardito, L., Cerchione, R., Del Vecchio, P., \& Raguseo, E. (2019). Big data in smart tourism: Challenges, issues, and opportunities. Current Issues in Tourism, 22(15), 1805-1809. doi:10.1080/13683500.2019.1612860

Bagozzi, R. (2007). The legacy of the technology acceptance model and a proposal for a paradigm shift. Journal of the Association for Information Systems, 8(4), 244-254. doi:10.17705/1jais.00122

Bennett, T. (2014). 7 Advantages of tourism in an economy. Blog.udemy.com. Available at: https://blog.udemy. com/advantages-of-tourism

Borràs, J., Moreno, A., \& Valls, A. (2014). Intelligent tourism recommender systems: A survey. Expert Systems with Applications, 41(16), 7370-7389. doi:10.1016/j.eswa.2014.06.007

Brasel, S., \& Gips, J. (2014). Tablets, touchscreens, and touchpads: Wow varying touch interfaces trigger psychological ownership and endowment. Journal of Consumer Psychology, 24(2), 226-233. doi:10.1016/j. jcps.2013.10.003

Chang, I., Chou, P., Yeh, R., \& Tseng, H. (2016). Factors influencing Chinese tourists' intentions to use the Taiwan medical travel app. Telematics and Informatics, 33(2), 401-409. doi:10.1016/j.tele.2015.09.007

Chao, C. M. (2019). Factors determining the behavioral intention to use mobile learning: An application and extension of the UTAUT model. Frontiers in Psychology, 10, 1652. doi:10.3389/fpsyg.2019.01652 PMID:31379679

Chen, X., \& Li, S. (2016). Understanding continuance intention of mobile payment services: An empirical study. Journal of Computer Information Systems, 57(4), 287-298. doi:10.1080/08874417.2016.1180649

Chen, Y., Hsu, I., \& Lin, C. (2010). Website attributes that increase consumer purchase intention: A conjoint analysis. Journal of Business Research, 63(9-10), 1007-1014. doi:10.1016/j.jbusres.2009.01.023

Dargah, D., \& Golrokhsari, H. (2012). E-tourism and customer satisfaction factors. International Journal of Advances in Management Science, 1, 35-40.

Davis, F. (1989). Perceived usefulness, perceived ease of use, and user acceptance of information technology. Management Information Systems Quarterly, 13(3), 319-339. doi:10.2307/249008

Davis, F. D. (1986). A Technology Acceptance Model for Empirically Testing New End-user information Systems: Theory and Results (Doctoral Dissertation). MIT Sloan School of Management, Cambridge, MA.

Devi, K., \& Verma, M. (2018). Web content and design trends of Indian Institute of Technology (IITs) libraries' website: An evaluation. COLLNET Journal of Scientometrics and Information Management, 12(2), $165-181$. doi:10.1080/09737766.2018.1433100

Dewanjee, R., \& Vyas, D. (2016). Cybercrime: critical view. International Journal of Science and Research, 5(1), 85-87. 
GoodWorkLabs. (2019). App development company for travel \& transport industry | Goodworklabs. GoodWorkLabs: Big Data I AI I Outsourced Product Development Company. Available at: https://www. goodworklabs.com/travel-and-transport-industry-app-development-solutions

Gretzel, U., Sigala, M., Xiang, Z., \& Koo, C. (2015). Smart tourism: Foundations and developments. Electronic Markets, 25(3), 179-188. doi:10.1007/s12525-015-0196-8

Guemide, B., Benachaiba, C., \& Maouche, S. (2019). Integrating ICT- Based Applications for Sustainable Tourism Development in Algeria. J Tourism Hospit, 8, 415. doi:10.35248/2167-0269.19.8.415

Hasan, B. (2016). Perceived irritation in online shopping: The impact of website design characteristics. Computers in Human Behavior, 54, 224-230. doi:10.1016/j.chb.2015.07.056

Hew, J., Lee, V., Ooi, K., \& Wei, J. (2015). What catalyzes mobile apps usage intention: An empirical analysis. Industrial Management \& Data Systems, 115(7), 1269-1291. doi:10.1108/IMDS-01-2015-0028

Hill, N., Brierley, J., \& MacDougall, R. (2019). How to Measure Customer Satisfaction (2nd ed.). Routledge Taylor \& Francis Group.

Hoehle, H., \& Venkatesh, V. (2015). Mobile application usability: Conceptualization and instrument development. Management Information Systems Quarterly, 39(2), 435-472. doi:10.25300/MISQ/2015/39.2.08

Khan, S. W. (2019), Cyber security issues and challenges in e-Commerce. Proceedings of 10th International Conference on Digital Strategies for Organizational Success, 1197-1204. Available at SSRN: https://ssrn.com/ abstract $=3323741$

Khraim, H. (2015). The impact of search engine optimization on online advertisement: The case of companies using e-Marketing in Jordan. American Journal of Business and Management, 4(2), 76-84. doi: $10.11634 / 216796061504676$

Kim, M., Chung, N., \& Lee, C. (2011). The effect of perceived trust on electronic commerce: Shopping online for tourism products and services in South Korea. Tourism Management, 32(2), 256-265. doi:10.1016/j. tourman.2010.01.011

Kisswani, N., \& Bakri, A. (2010). Security, ethics, and electronic commerce systems: Cybercrime and the need for information sharing security. International Journal of Liability and Scientific Enquiry, 3(3), 225-237. doi:10.1504/IJLSE.2010.033357

Ku, E., \& Chen, C. (2015). Cultivating travelers' revisit intention to e-tourism service: The moderating effect of website interactivity. Behaviour \& Information Technology, 34(5), 465-478. doi:10.1080/0144929X.2014.978376

Kumar, D., \& Goyal, N. (2016). Security issues in M-commerce for online transaction. 2016 5th International Conference on Reliability, Infocom Technologies and Optimization (Trends and Future Directions) (ICRITO), 409-414. doi: 10.1109/ICRITO. 2016.7784990

Lai, P. (2017). The literature review of technology adoption models and theories for the novelty technology. Journal of Information Systems and Technology Management, 14(1), 21-38. doi:10.4301/S1807-17752017000100002

Maduku, D. (2016). The effect of institutional trust on internet banking acceptance: Perspectives of South African banking retail customers. Suid-Afrikaanse Tydskrif vir Ekonomiese en Bestuurswetenskappe, 19(4), 533-548. doi:10.4102/sajems.v19i4.1558

O.T.T. (2019). 12 real cases of application of Artificial Intelligence to the travel industry. Available online at https://onlinetraveltechnology.com/en/12-real-cases-of-application-of-artificial-intelligence-to-the-travel-industry

Oumlil, R., \& Ouhamane, Y. (2016). Do TAM Constructs Predict E-tourism Adoption by Hotels in Agadir City South of Morocco? In V. Katsoni \& A. Stratigea (Eds.), Tourism and Culture in the Age of Innovation. Springer Proceedings in Business and Economics (pp. 603-616). Springer. doi:10.1007/978-3-319-27528-4_41

Perea y Monsuwé, T., Dellaert, B., \& de Ruyter, K. (2004). What drives consumers to shop online? a literature review. International Journal of Service Industry Management, 15(1), 102-121. doi:10.1108/09564230410523358

Pickens, J. (2005). Attitudes and perceptions. In N. Borkowski (Ed.), Organizational Behavior in Health Care (pp. 43-76). Jones \& Barlett Publishing. Available at http://healthadmin.jbpub.com/borkowski/chapter3.pdf 
Pitoska, E. (2013). E-tourism: the use of internet and information and communication technologies in tourism: the case of hotel units in peripheral areas. Tourism in Southern and Eastern Europe.

Prasidya, T. (2018). Effect of quality of service, quality products, security, and satisfaction as moderating variables to loyalty on e-banking. Russian Journal of Agricultural and Socio-Economic Sciences, 83(11), 109-113. doi:10.18551/rjoas.2018-11.12

Qatawneh, A., Aldhmour, F., \& Alfugara, S. (2015). The adoption of electronic payment system (EPS) in Jordan: Case study of Orange Telecommunication Company. Research Journal of Finance and Accounting, 6(22), 139-148.

Richard, J. E., Thirkell, P., \& Huff, S. L. (2007). An Examination of Customer Relationship Management (CRM) Technology Adoption and its Impact on Business-to-Business Customer Relationships. Total Quality Management \& Business Excellence, 18(8), 927-945. doi:10.1080/14783360701350961

Robbins, S., \& Judge, T. (2018). Organizational behavior (16th ed.). Pearson Education.

Sahli, A. B., \& Legohérel, P. (2015). The tourism Web acceptance model: A study of intention to book tourism products online. Journal of Vacation Marketing, 22(2), 179-194. doi:10.1177/1356766715607589

Sahli, A. B., Legohérel, P., Kucukusta, D., \& Law, R. (2016). A Cross-Cultural Validation of the Tourism Web Acceptance Model (T-WAM) in Different Cultural Contexts. Journal of International Consumer Marketing, 28(3), 211-226, doi: 10.1080 /08961530. 2016.1152524

Shafiee, M., Rahimzadeh, S., \& Haghighizade, R. (2016). The effect of implementing SEO techniques and websites design methods on e-Tourism development: a study of travel agencies e-Tourism websites. 10th international conference on e-commerce with focus on e-tourism, 1-8. doi:10.1109/ECDC.2016.7492963

Slade, E., Dwivedi, Y., Piercy, N., \& Williams, M. (2015). Modeling consumers' adoption intentions of remote mobile payments in the United Kingdom: Extending UTAUT with innovativeness, risk, and trust. Psychology and Marketing, 32(8), 860-873. doi:10.1002/mar.20823

Statista. (2019). Travel \& tourism: global economic impact 2017 I Statistic. Available at: https://www.statista. com/statistics/233223/travel-and-tourism--total-economic-contribution-worldwide

Suh, B., \& Han, I. (2002). Effect of trust on customer acceptance of Internet banking. Electronic Commerce Research and Applications, 1(3-4), 247-263. doi:10.1016/S1567-4223(02)00017-0

Tan, G., Lee, V., Lin, B., \& Ooi, K. (2017). Mobile applications in tourism: The future of the tourism industry? Industrial Management \& Data Systems, 117(3), 560-581. doi:10.1108/IMDS-12-2015-0490

Tussyadiah, I., Li, S., \& Miller, G. (2019). Privacy Protection in Tourism: Where We Are and Where We Should Be Heading For. In J. Pesonen \& J. Neidhardt (Eds.), Information and Communication Technologies in Tourism 2019 (pp. 278-290). Springer. doi:10.1007/978-3-030-05940-8_22

Ukpabi, D., \& Karjaluoto, H. (2017). Consumers' acceptance of information and communications technology in tourism: A review. Telematics and Informatics, 34(5), 618-644. doi:10.1016/j.tele.2016.12.002

UXarabia. (2019). Learn UX Design - Video Courses - UX arabia. Available at: http://uxarabia.com

Venkatesh, V., \& Bala, H. (2008). Technology acceptance model 3 and a research agenda on interventions. Decision Sciences, 39(2), 273-315. doi:10.1111/j.1540-5915.2008.00192.x

Venkatesh, V., \& Davis, F. (2000). A theoretical extension of the technology acceptance model: Four longitudinal field studies. Management Science, 46(2), 186-204. doi:10.1287/mnsc.46.2.186.11926

Venkatesh, V., Morris, M. G., Davis, G. B., \& Davis, F. D. (2003). User acceptance of information technology: Toward a unified view. Management Information Systems Quarterly, 27(3), 425-478. doi:10.2307/30036540

Wang, H., Liao, C., \& Yang, L. (2013). What affects mobile application use? the roles of consumption values. International Journal of Marketing Studies, 5(2), 11-22. doi:10.5539/ijms.v5n2p11

Yang, Y., \& Stienmetz, J. L. (2018). Big data and tourism planning. Information Technology \& Tourism, 20(1-4), 189-190. doi:10.1007/s40558-018-0127-6 
Yoon, H., \& Occeña, L. (2015). Influencing factors of trust in consumer-to-consumer electronic commerce with gender and age. International Journal of Information Management, 35(3), 352-363. doi:10.1016/j. ijinfomgt.2015.02.003

Zaidan, E. (2016). Analysis of ICT usage patterns, benefits, and barriers in tourism SMEs in the Middle Eastern countries. Journal of Vacation Marketing, 23(3), 248-263. doi:10.1177/1356766716654515

Zhou, T. (2013). An empirical examination of continuance intention of mobile payment services. Decision Support Systems, 54(2), 1085-1091. doi:10.1016/j.dss.2012.10.034

Zhou, T. (2014). An empirical examination of initial trust in mobile payment. Wireless Personal Communications, 77(2), 1519-1531. doi:10.1007/s11277-013-1596-8

Zlatanov, S., \& Popesku, J. (2019). Current applications of artificial intelligence in tourism and hospitality. Conference Proceedings: International Scientific Conference on Information Technology and Data Related Research, 84-90. doi:10.15308/Sinteza-2019-84-90

Ghazi Alkhatib is a retired academician from the Hashemite University in 2017. In 1984, he obtained his Doctor of Business Administration from Mississippi State University in Information Systems with minors in Computer Science and Accounting. Since then, he has been engaged in teaching, consulting in IT strategic planning, training, and research in the area of Computer Information Systems in the US, Gulf countries, and Jordan. In addition to his research interests in databases and systems analysis and design, he has published over 80 manuscripts in second and third tier indexed journals and proceedings in regional and international conferences covering all continents on software processes, knowledge management, data mining, e-business, Web services/agent software integration, workflow, portal/grid computing integration with Web services, strategic planning, and ERP implementation. He is the founder and Editor-in-Chief of the International Journal of IT and Web Engineering, and Series Editor of the Advances in Web Technologies and Engineering Book Series, both since 2006. He is also a member of the Academic Advisory Board - all at IGI Global Publisher, USA.

Sinamis Tahsin Bayouq has a BS degree from the University of Jordan in Computer Information Systems in 2005 , and an MBA from the University of Bedfordshire (UoB) in Management in 2019. She was employed as a programmer and systems analyst at the Income \& Sales Tax Department (ISTD) to assess and upgrade the capabilities of internal workflow programs, and supported ISTD as a coordinator with the USAID to develop projects and programs like the E-Government. In addition, she worked in the academic field as an IT instructor at Amman National School (ANS). Mrs. Bayouq was also responsible for preparing educational, training and evaluation plans for high school students in national and international programs. 